\title{
Modelling Public Knowledge and Attitude towards Genetically Modified Maize in Kenya
}

\author{
Ezrah Kipkirui Tonui
}

\begin{abstract}
A survey of 138 farmers was conducted in Rift valley, Kenya, in November and December 2013 in three counties (Uasingishu, Elgeyo-marakwet, and Trans-Nzoia) to determine public knowledge and attitude towards genetically modified (GM) maize.Most of the respondents in Trans-Nzoia were female (18\%) while male were (16\%) though generally there was 50\% participation in both gender. Above two third (70\%) of the respondents had knowledge of GM maize, mostly those educated and male. Female was found to be having low knowledge on GM maize. Public acknowledged the technology's potential positive impacts, with more than $90 \%$ willing to adopt and more than $98 \%$ willing to buy GM seedlings at any given price. A small percentage less than $3 \%$ were of a negative opinion about willing to buy and adopt GM seeds. Both male and female were willing to adopt GM maize (Both are 48\%) while the higher percentage of those with college education were willing to adopt (25\%). Female were more willing to buy (50\%) than the male (49\%) and all respondents with all levels of education were equally willing to buy the GM seeds at any given market price. The survey shows a society with positive attitude towards biotechnology which could play a major role in food security in Kenya. However, the public need more information about the technology, this study identified an important source of communication of biotechnology as use of radio which is the foremost source of communication. Finally, public knowledge and attitude on GM maize should be studied on a regular basis, and the survey population broadened to 47 counties.
\end{abstract}

Keywords: Public; Knowledge; attitudes; GM maize; Kenya

\section{Introduction}

Genetically modified food has potential benefits particularly for developing countries which were recognized as including; increasing the availability of food, feed and renewable raw materials; improving human health; Enhancing protection of the environment; Enhancing safety and developing international mechanisms for cooperation; Establishing enabling mechanisms for the development and the environmentally sound application of biotechnology. Studies have verified that many consumers in the European Union have difficulties accepting GM products. Verdurme and Viaene (2002) observed that consumers (especially in the EU and Japan) oppose theuse of GM technology in food production. Consumers in the USA, on the other hand, are generally willing to accept GM food if sufficient price discounts are made on them (Kaneko and Chern, 2003).

Li et al. (2002) observed that although the majority of Chinese consumers reported that they had little or no knowledge of biotechnology, their attitudes toward GM foods was generally positive, translating to a willingness to pay a premium for GM rice and soybean, and hence their acceptance of these foods. Compared to developed countries (UK and USA), Curtis et al. (2004) observe that generally, consumers in developing countries (China and Columbia) have more positive perceptions towards GM foods, most likely stemming from more urgent food needs, more positive media influence, higher trust in government, and a more positive perception of science.

Other key factors that influence consumer acceptance of GM foods are awareness and information. Consumers who are better informed about GMOs are more likely to perceive the risks of genetic modification, but they are also more likely to perceive the benefits.

It has therefore, often been found that consumer attitudes towards genetically modified foods can reasonably well be predicted by general socio-political attitudes or values. Among these are, for example, attitudes towards technological progress (Bredahl, 2001) and attitudes towards environment and nature (Bredahl, 2001). Research in this tradition has mainly been carried out by academic researchers who use multivariate statistical techniques to model the internal and external structure of whole attitude systems. Results suggest that attitudes towards genetically modified foods may have value expressive functions to consumers rather than being the result of a risk-benefit tradeoff as assumed by models of technical rationality (Frewer et al, 2003). Interestingly, this conclusion is in sharp contrast with common interpretations of opinion poll data. The supposition that risk perceptions may be off set by perceptions of benefit has lead many scientists and industrialists to assume that if only a particularly desirable benefit can be developed in the context of genetically modified foods, then public acceptance would result. There was therefore no reason why people would automatically accept novel foods that had health benefits, independent of additional concern about the technological approach used to produce them. Hence introducing consumer benefits associated with particular foods is unlikely to result in a general acceptance of genetically modified foods rather some consumers will be very positive towards some products, others would prefer alternative food choices.

Public knowledge and attitude towards GM maize would ultimately be the deciding factor in determining the development of biotechnology for many countries with vast implications for international trade, particularly for agricultural commodities. In today's society, public opinion is extremely unpredictable. Regardless of whether public information originated from scientists trying to project a specific image or from a journalistic impression, the variable nature of a community's attitude on issues of science and technology was directly influenced by the manner in which the public was informed about the current circumstance (Tapestry, 2000). While scientists created new technologies and determined whether a particular product or condition

Volume 6 Issue 12, December 2017 


\section{International Journal of Science and Research (IJSR) \\ ISSN (Online): 2319-7064}

Index Copernicus Value (2016): 79.57 | Impact Factor (2015): 6.391

may be harmful, the media decided how the information is presented.

The inconsistencies between scientific explanations of new discoveries and the media's presentation of the explanations resulted in public fear of technology, misinformed individuals, and the unpredictable public perceptions. As history proved, the public's recent criticisms toward science had merit. For example, the horror of the atomic bomb, chemical warfare, the depletion of the ozone layer and the "greenhouse effect," cancer-causing chemicals, and the exhaustion of fossil fuels all represented past failures to anticipate and control negative effects of scientific advances. These misfortunes justify the instigation of a more disparaging evaluation of advances in science and technology by the public. Science was no longer assumed to be innately good simply because it was based on logic (Ronzheimer, 1999), the public had a more pessimistic attitude towards new advances in Science and technology, more questions must be answered and addressed before new paradigms are accepted. Unfortunately, simply providing more information, performing new tests, and analyzing new situations will not necessarily increase public understandings.

Firstly, the public wanted absolute proof that the new product is harmless, or the invention will work and improve their standard of living; however, scientists are often unable to reply to the skepticism with a definite "yes" or "no" or "we're $100 \%$ sure." Many people did not understand and accept that laboratory conditions did not generate $100 \%$ accurate information; sometimes $83 \%$ is their best guess. Another source of inconsistency within the reporting of scientific information is the limited amount of time scientists devote to public education. Especially within the academic community, scientists are too busy competing for grants and funding for research and discussing new ideas among themselves to interact with the general public.

In our industrialized society, scientific ideas had become a marketable commodity in a competitive market as a result of interventions from corporations, politicians, and the media. Public spending on research is declining as a result of this privatization of science; consequently, causing an increase in competition for research dollars and less time for public education. Besides decreasing public research in general, the privatization of science led tothe distrust of many scientist and engineers who worked for private firms. Of course no oneis going to believe the "expert" sent from the nuclear power plant, he or she was probably paid to promote his or her firm.

The public tends to favor those in opposition to science and technology because the opponents share the same fears as the public. As Ray describes, "In such a format, the opposition always "wins," because whoever is against any technology has only to make a charge, however preposterous, and doesn't have to prove it. That burden falls upon the supporter of science to prove that the charge is groundless. Even the smartest of scientists would struggle to refute someone else's idea on the spot, especially if the idea did not flow from the logical school of scientific thought. Aside from problems introduced by the scientists that contribute to public misunderstandings, the entire structure of the media system introduces a foundation for misconceptions. Even if a journalist were able to perform the seemingly impossible task of accurately translating scientific ideas into everyday language, the clearly understandable explanations would be deleted in editing the article to fit in a two-inch column of a newspaper.

Finally, the public misconceptions about science can also be attributed to the public itself and society's general ignorance of simple scientific facts. Recent surveys of public scientific literacy in several major industrialized nations reported that the public lacks knowledge that the Earth revolves around the sun, or that antibiotics are ineffective against viruses (Ronzheimer, 1999). Public perception determines what products are purchased, what politicians are elected, what laws are passed, how global problems are solved, and is the core of a functioning society. This study will be analyzing public understanding and attitude towards genetically modified maize by using focus group analysis.

\section{Materials and Methods}

The kind of data that we are going to use in this study is dichotomous and the most preferable model to be applied in this case is logistic model because we need a model where the outcome side of the regression equation is constrained to be in the interval $(0,1)$. On the prediction side of the equation, we want no bounds, similar to linear regression. To this end, the logistic function was dreamed up, which satisfies these two properties. (Kleinbaum and Klein, 2002, p.5-6). Kleinbaum and Klein's argument provides a level of credibility to the logistic function, since logistic regression predicts risk. That is, logistic regression predicts the proportion of 1's in the outcome variable, while forcing the logistic function shape on the predicted values. Like all GLMs, logistic regression assumes that the probability distribution for the response variable, and hence for the error terms from the fitted model is adequately described by the random component chosen. Secondly, we assume that the binomial and Poisson distributions are appropriate which is likely for binary data. Logistic regression does not make any assumptions of normality, linearity, and homogeneity of variance for the independent variables.A further consequence is the linear model which cannot be directly applied to case-control data since the error cannot be estimated from such designs without additional information. There is an additional structural drawback to use of the linear model with binary outcome data. Whatever the value of the parameters $a$ and $b(\neq 0)$, at some values in the range of $X$, either low values or high values. This may not be a practical concern when this occurs for $X$ values that are far from those observed in the population. However, in cases where the errors are either very low or very high, the true values of errors are already very close to these boundaries, and it may be safer to use a model that does not allow for negative errors or errors greater than one.

\section{Volume 6 Issue 12, December 2017}




\section{International Journal of Science and Research (IJSR) \\ ISSN (Online): 2319-7064 \\ Index Copernicus Value (2016): 79.57 | Impact Factor (2015): 6.391}

\section{Modeling Public Knowledge and Attitude towards Genetically Modified Maize}

To identify and estimate the influence of public knowledge and attitude on the GM maize, we develop a binary logistic model a profile of likely consumers of GM maize products. The logistic model is commonly used in the situations with a binary dependent variable because the asymptotic characteristics of the model constrain the predicted probabilities between 0 and 1 . The logistic model is estimated by the maximum likelihood method because of its consistent and asymptotic effect.In this econometric model, $\mathrm{P}_{\mathrm{i}}$ is assumed as the probability of public knowledge on GM maize. It depends on a matrix of independent variables $\mathrm{X}_{i j}$, where $\mathrm{i}$ denotes the $i^{\text {th }}$ respondent, and $\mathrm{j}$ denotes the $j^{\text {th }}$ independent variable, which is consisted of public's personal characteristics such as gender and age, his/her socioeconomic variables and so forth. This model can be formalized as follows:

$$
P i=F(Z i)=F\left(\beta \kappa i^{\prime}\right)=1 /[1+\exp (-Z i)] \ldots
$$

where, $\mathrm{F}\left(\mathrm{Z}_{i}\right)$ is used to denote the value of logistic cumulative de

nsity function (CDF) associated with each possible value of the underlying index $Z_{i}$, which equals to an unobserved index level or the log odds of choice for the $i^{\text {th }}$ observation, and which can be formalized as equation (2) because of $\beta X_{i}^{\prime}$ is a linear combination of the independent variables in equation (1); $\beta=\left(\beta_{0}, \beta_{1} \ldots . . \beta_{\mathrm{j}}\right)$ is a vector of parameters we will estimate.

$$
Z i=\log [P i /(1-P i)]=\beta \kappa i+\varepsilon i, i=1,2, \ldots, \mathrm{n} . .
$$

In equation (2), $X_{i}$ is assumed be equal to $(1,1, \ldots \ldots, 1)^{\prime}$ such that $\beta_{0}$ represents the intercept of equation (2); In such model, the marginal effects of independent variables on $P i$ are given by:

$$
\delta P i / \delta \kappa i j=P(Y i: X i j=1)-P(Y i: X i j=0) \ldots
$$

Therefore,

$$
\text { Logistic function: } f(z)=\frac{1}{1+e^{-z}}
$$

We let $\mathrm{z}$ represent the right hand side of a linear model (Kleinbaum and Klein, p.7-8):

$$
\mathrm{z}=\alpha+\beta_{1} \mathrm{X}_{1}+\ldots+\beta_{\mathrm{k}} \mathrm{X}_{\mathrm{k}}
$$

Substituting for $\mathrm{z}$ in the logistic function, we have:

$$
f(z)=\frac{1}{1+e^{-z}}=\frac{1}{1+e^{-\left(\alpha+\sum \beta_{i} X_{i}\right)}}
$$

For the independent (predictor) variables $X_{i}$, and for $\mathrm{D}=1$ representing knowledge, we write the probability of knowledge $\mathrm{f}(\mathrm{z})$ as

$\mathrm{P}(\mathbf{X})=\mathrm{P}\left(\mathrm{D}=1 \mid \mathrm{X}_{1}, \mathrm{X}_{2}, \ldots, \mathrm{X}_{\mathrm{k}}\right)=f(z)=\frac{1}{1+e^{-\left(\alpha+\sum \beta_{i} X_{i}\right)}}$

which is the prediction equation and $\beta_{\mathrm{i}}$ are parameters to be estimated.

\section{Properties of the Fitted Models}

For us to know the unbiasedness of the model we test the $\wedge$ $\wedge$ unbiasedness of the estimators, hence $E\left(\beta_{0}\right)$ and $E\left(\beta_{1}\right)$. We need to use the law of iterated expectations which states that for random variables $\mathrm{W}$ and $\mathrm{Z}$; $\mathrm{E}[\mathrm{E}(\mathrm{Z} \mid \mathrm{W})]=\mathrm{E}[\mathrm{Z}]$ this means that $\mathrm{E}\left[\mathrm{E} \beta_{1}{ }^{\wedge} \mid \mathrm{x}_{1}, \mathrm{x}_{2 \ldots \ldots . . .} \mathrm{x}_{\mathrm{n}}\right]=\mathrm{E}\left(\beta_{1}{ }^{\wedge}\right)$ which further means that if we can show that $\mathrm{E}\left(\beta_{1} \mid \mathrm{x}_{1}, \mathrm{x}_{2} . . \mathrm{x}_{\mathrm{n}}\right)=\beta_{1}$ then $\wedge$

$E\left(\beta_{1}\right)=\beta_{1}$

First we will make use of the fact that

$$
\hat{\beta} 1=\frac{\sum_{j=1}^{N}\left(x_{j}-\bar{x}\right)\left(y_{i}-\bar{y}\right)}{\sum_{j=1}^{N}(x-\bar{x})^{2}}=
$$

$$
\frac{\sum_{j=1}^{N}\left(x_{i}-\bar{x}\right)\left(\beta_{0}+\beta_{1} x_{i}+u_{i}-\beta_{0}-\beta_{1} \bar{x}-\bar{u}\right)}{\sum_{i=1}^{N}\left(x_{i}-\bar{x}\right)^{2}}
$$

$=\frac{\sum_{i=1}^{N}\left(x_{i}-\bar{x}\right)\left(\beta_{1} x_{i}-\beta_{1} \bar{x}\right)}{\sum_{i=1}^{N}\left(x_{i}-\bar{x}\right)^{2}}+\frac{\sum_{i=1}^{N}\left(x_{i}-\bar{x}\right)\left(u_{i}-\bar{u}\right)}{\sum_{i=1}^{N}\left(x_{i}-\bar{x}\right)^{2}}$

$=\beta_{1}+\frac{\sum_{i=1}^{N}\left(x_{i}-\bar{x}\right)\left(x_{i}-\bar{x}\right)}{\sum_{i=1}^{N}\left(x_{i}-\bar{x}\right)^{2}}+\frac{\sum_{i=1}^{N}\left(x_{i}-\bar{x}\right)\left(u_{i}-\bar{u}\right)}{\sum_{i=1}^{N}\left(x_{i}-\bar{x}\right)^{2}}$

$$
=\beta_{1}+\frac{\sum_{i=1}^{N}\left(x_{i}-\bar{x}\right)\left(u_{i}-\bar{u}\right)}{\sum_{i=1}^{N}\left(x_{i}-\bar{x}\right)^{2}}
$$

Then notice that

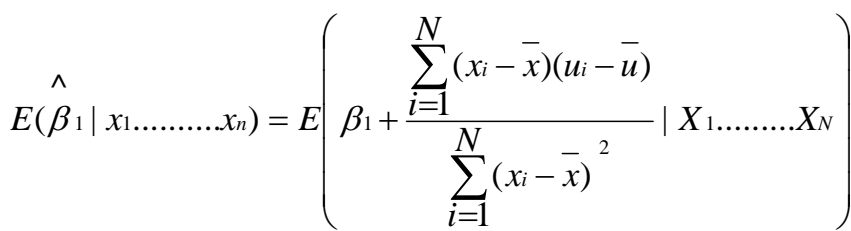

$$
\begin{aligned}
& =\beta_{1}+\frac{\sum_{i=1}^{N}\left(x_{i}-\bar{x}\right) E\left(u_{i}-\bar{u} \mid X_{1} \ldots \ldots \ldots . . . X_{N}\right)}{\sum_{i=1}^{N}\left(x_{i}-\bar{x}\right)^{2}}
\end{aligned}
$$




\section{International Journal of Science and Research (IJSR) \\ ISSN (Online): 2319-7064}

Index Copernicus Value (2016): 79.57 | Impact Factor (2015): 6.391

This means that $\beta_{1}$ is Unbiased.

Secondly, we want to look at how well our model fits the data (goodness of fit). We will make use of the following three things:

Total sum of squares (SST):

$$
\mathrm{SST}=\sum_{i=1}^{N}\left(y_{i}-\bar{y}\right)^{2}
$$

Explained sum of squares (SSE):

$$
\mathrm{SSE}=\sum_{i=1}^{N}\left(\hat{y}_{i}-\bar{y}\right)^{2}
$$

Residual sum of squares (SSR):

$$
\mathrm{SSR}=\sum_{i=1}^{N} \hat{u} i^{2}
$$

It turns out that there is a nice relationship between these concepts.

$$
\begin{aligned}
& \operatorname{SST}=\sum_{i=1}^{N}\left(y_{i}-\bar{y}\right)^{2}=\sum_{i=1}^{N}\left(\left(y_{i}-\hat{y_{i}}\right)+\left(\hat{\left.y_{i}-\bar{y}\right)}\right)^{2}\right. \\
& \left.=\sum_{i=1}^{N} \hat{\left(u_{i}+\left(y_{i}-\bar{y}\right)\right)^{2}}=\sum_{i=1}^{N} \hat{\left[u_{i}+\left(y_{i}-\bar{y}\right)\right.}\right)^{2}+2 \hat{\left.u_{i}\left(y_{i}-\bar{y}\right)\right]} \\
& \left.=\sum_{i=1}^{N} \hat{u}_{i}^{2}+\sum_{i=1}^{N} \hat{(y i}_{i}-\bar{y}\right)^{2}+\sum_{i=1}^{N} \hat{\wedge} \hat{u_{i}\left(y_{i}-\bar{y}\right)} \\
& =\mathrm{SSR}+\mathrm{SSE}+\sum_{i=1}^{N} \hat{\wedge} \hat{\wedge}
\end{aligned}
$$

Therefore,

$$
\begin{aligned}
& \sum_{i=1}^{N} \hat{\wedge} \hat{u_{i}}\left(\hat{y}_{i}-\bar{y}\right)=2 \sum_{i=1}^{N} \hat{u_{i}}\left(\left(\hat{\beta}_{0}+\hat{\beta}_{1} X_{i}\right)-\left(\hat{\beta}+\hat{\beta_{0}} \overline{X_{i}}\right)\right) \\
& =2 \sum_{i=1}^{N} \hat{u_{i}}\left(\beta_{1} X_{i}-\hat{\beta_{1}} \bar{X}\right)=2 \hat{\beta_{1}} \sum_{i=1}^{N} \hat{u_{i} X_{i}}-2 \hat{\beta} \bar{X} \bar{X} \sum_{i=1}^{N} \hat{u_{i}} \\
& =0
\end{aligned}
$$

\begin{tabular}{|c|c|c|c|c|c|}
\hline & & \multicolumn{4}{|c|}{ County } \\
\hline & & $\begin{array}{c}\text { Tran-Nzoia } \\
(\mathrm{N} 1=46)\end{array}$ & $\begin{array}{c}\text { Elgeyo } \\
\text { Marakwet } \\
(\mathrm{N} 2=46)\end{array}$ & $\begin{array}{l}\text { Uasin- } \\
\text { Gishu } \\
(\mathrm{N} 3=46)\end{array}$ & Total \\
\hline Variable & Category & $(\%)$ & $(\%)$ & $(\%)$ & $(\%)$ \\
\hline \multirow[b]{2}{*}{ Gender } & Female & 18 & 15 & 18 & 50 \\
\hline & Male & 16 & 18 & 16 & 50 \\
\hline \multirow{3}{*}{$\begin{array}{l}\text { Level of } \\
\text { education }\end{array}$} & College & 5 & 0 & 21 & 26 \\
\hline & Secondary & 19 & 0 & 18 & 37 \\
\hline & Primary & 20 & 0 & 17 & 37 \\
\hline $\begin{array}{c}\text { Drought } \\
\text { years }\end{array}$ & $\begin{array}{c}\text { in last } \\
10 \text { years }\end{array}$ & 33 & 42 & 25 & 100 \\
\hline
\end{tabular}

Thus SST $=$ SSE + SSR

This gives us a really nice way of describing the goodness of fit of the model

$$
R^{2}=\frac{S S E}{S S T}=1-\frac{S S R}{S S T}
$$

Hence is good for the data.

\section{Application of Model to the Counties}

Social economic characteristics
Table 1

The basis for targeting three counties was the need to incorporate views of diverse categories of the public, based on the assumption that there are distinct differences in socioeconomic characteristics that may influence knowledge and attitudes toward GM maize. The survey results clearly confirm these differences (Table 1). Eighteen percent (18\%) of the respondents in Trans-Nzoia were female, while $(16 \%)$ percent were male. In Elgeyo marakwet, male were $18 \%$ while female were $15 \%$ and the county has the highest drought years in the last 10 years. Uasin-gishu had the highest percentage of those with college education, and also the lowest drought years in the last 10 years. This indicates that people in the higher socioeconomic categories do maize farming more frequently than those with lower social economic categories.

Public knowledge of GM maize by socioeconomic characteristics

Table 2

\begin{tabular}{|c|c|c|c|c|}
\hline \multirow{2}{*}{ Variable } & \multirow{2}{*}{ Category } & \multicolumn{2}{|c|}{$\begin{array}{c}\text { \% Of respondents aware of: } \\
\text { Gm Maize }\end{array}$} & \multirow{2}{*}{ Total } \\
\cline { 3 - 5 } & & Yes & No & \\
\hline \multirow{2}{*}{ Gender } & Female & 25 & 10 & 35 \\
\cline { 2 - 5 } & Male & 55 & 10 & 65 \\
\hline \multirow{3}{*}{$\begin{array}{c}\text { Level of } \\
\text { education }\end{array}$} & College & 25 & 0 & 25 \\
\cline { 2 - 5 } & Secondary & 22 & 3 & 25 \\
\cline { 2 - 5 } & Primary & 14 & 11 & 25 \\
\cline { 2 - 5 } & None & 24 & 1 & 25 \\
\hline
\end{tabular}

In overall, an average of $80 \%$ of all the respondents had heard or read something about GM maize. Those who had knowledge about GM maize were $25 \%$ being female and $55 \%$ being male. The results on the table 2 imply that people in the higher level of education are more aware of GM maize $(25 \%$ in college while $22 \%$ had secondary level of education). Knowledge about particular GM crops did not differ by counties or by socioeconomic characteristics. Analysis of the knowledge of GM maize shows clear differences by socioeconomic characteristics (Table 2). Male had more knowledge than female $(55 \%$ and $25 \%$ respectively), and knowledge varies by education level category, from those gone to college (25\%), over the Secondary level $(22 \%)$ to the primary $(14 \%)$ and those whose education level was not indicated was $(24 \%)$. 


\section{International Journal of Science and Research (IJSR) ISSN (Online): 2319-7064}

Index Copernicus Value (2016): 79.57 | Impact Factor (2015): 6.391

Public attitudes on GM maize (expressed as percentage of respondents).

Table 3

\begin{tabular}{|c|c|c|c|c|c|c|}
\hline \multirow{3}{*}{$\begin{array}{c}\text { Type of } \\
\text { perception }\end{array}$} & \multirow{3}{*}{ Variable } & & \multirow{2}{*}{\multicolumn{2}{|c|}{ Disagree $\begin{array}{l}\text { Don't } \\
\text { know }\end{array}$}} & \multirow[b]{2}{*}{ Total } \\
\hline & & Category & Agree & & & \\
\hline & & & $(\%)$ & $(\%)$ & $(\%)$ & $(\%)$ \\
\hline \multirow{6}{*}{$\begin{array}{c}\text { Willingness } \\
\text { to adopt }\end{array}$} & \multirow{2}{*}{ Gender } & Female & 48 & 1 & 2 & 50 \\
\hline & & Male & 48 & 3 & 0 & 50 \\
\hline & \multirow{4}{*}{$\begin{array}{l}\text { Level of } \\
\text { education }\end{array}$} & College & 25 & 0 & 0 & 25 \\
\hline & & Secondary & 24 & 2 & 0 & 25 \\
\hline & & \begin{tabular}{|l|} 
Primary \\
\end{tabular} & 24 & 1 & 0 & 25 \\
\hline & & None & 25 & 1 & 0 & 25 \\
\hline \multirow{6}{*}{$\begin{array}{l}\text { Willingness } \\
\text { to buy }\end{array}$} & \multirow{2}{*}{ Gender } & Female & 50 & 0 & 0 & 50 \\
\hline & & Male & 49 & 0 & 0 & 50 \\
\hline & \multirow{4}{*}{$\begin{array}{l}\text { Level of } \\
\text { education }\end{array}$} & College & 25 & 0 & 0 & 25 \\
\hline & & Secondary & 25 & 0 & 0 & 25 \\
\hline & & Primary & 25 & 0 & 0 & 25 \\
\hline & & None & 25 & 0 & 0 & 25 \\
\hline
\end{tabular}

Public attitudes on GM maize were determined using 2 variables representing perception of benefits, environmental risk, health risk. However, to facilitate the analysis, "Disagree" and "agree" were used as shown in Table 3. Itshows the percentage of farmers that completed the statements with "agree", "disagree", and "don't know." Most people believed in the technology's potential positive impacts, with $96 \%$ of both gender agreeing that it could offer a solution to the world's food problems and were willing to adopt, $99 \%$ of the respondents of both gender were willing to buy the Gm seeds at any given price. However, a small number of farmer's expressed concerns about potential negative effects, the respondents who were not willing to adopt were $4 \%$ while none ( $0 \%$ ) were not willing to buy GM maize seeds at the prevailing market prices.To assess consumers' willingness to pay for GM maize meal, people were first asked whether they would buy it at the same price as their favorite brand, and then asked if they would purchase it if offered at a premium or a discount, depending on their response to the initial question.

\section{Fitting the model}

Our logistic model is: $\mathrm{f}\left(\mathrm{z}_{\mathrm{i}}\right)=\frac{1}{1+\exp -\left(\beta o+\beta 1 X_{1}+\beta_{2} X_{2}\right)}$

$$
\beta o=0.3843 \beta 1=0.1136 \quad \beta 2=0.2137
$$

\section{1}

$\overline{1+\exp -\left(0.3843+0.1136 X_{1}+0.2137 X_{2}\right)}$

This therefore is our model.

This model is good as it can be seen from the r-squared which is the value above $50 \%$.

Our logistic model is: $\mathrm{f}\left(\mathrm{z}_{\mathrm{i}}\right)=\frac{1}{1+\exp -\left(\beta o+\beta 1 X_{1}+\beta_{2} X_{2}\right)}$

$\beta o=0.3843 \beta 1=0.1136 \quad \beta 2=0.2137$

$=\frac{1}{1+\exp -\left(0.3843+0.1136 X_{1}+0.2137 X_{2}\right)}$

This therefore is our model.

This model is good as it can be seen from the r-squared which is the value above $50 \%$.

\section{Discussion}

The success of a genetically modified crop program will depend on the acceptability of its products by consumers, so it is important to determine the opinions of the public on such technologies (Kimenju et al). The results of this farmer's survey shown that more than two-third of the farmers in the counties surveyed were aware of GM crops, so it is generally possible to engage them in the debate. However, knowledge, sources of information, and attitudes varied by level of education, gender and socioeconomic grouping.

To have a representative picture while tracking farmers opinions, it should be ensured that all categories of farmers are included (both small scale \& large scale) because different categories may present different views. The core of the controversy over GM crops is the extent to which consumers perceive benefits from the technology relative to its risks, as this will determine acceptability. Generally, people are appreciative of the positive benefits of the technology, although many are worried about potential negative effects. The government, the IRMA project, and a range of stakeholders face an important challenge in communicating the advantages and disadvantages of the technology to the general public. In particular, they should aim to inform the public that GM foods, based on extensive scientific testing, are now generally accepted as safe for human and animal consumption by national and international research institutions and others (FAO, 2004). This study has identified the important sources of information for the rural Kenyan farmer, which can serve as a starting point for effectively targeted communication on GM crops in the future as mass media and radio communication and (ISAAA, 2011), followed by schools/colleges. In such communication efforts, newspapers and television should be specifically used totarget people of high socioeconomic status, while the radio can specifically target the lower socioeconomic groups. The farmers' surveyed generally had a positive attitude towards GM maize suggesting that the technology could play a major role in food security in Kenya. However, emphasis must also be given to educating people about the technology by providing them factual information. Finally, studies tracking public opinion should be conducted regularly, in order to determine knowledge levels, capture the impact of knowledge activities, and reveal trends. Studies should be extended to the 47 counties, in order to include these segments of the population in the national discourse. The present study provided some important insights to improve the methodology. First, the different counties represent different types of consumers. However, the number and respective percentage of people that do farming activity in each county is not known. Household surveys could solve this problem, and they are therefore highly recommended. Further, future surveys can move from open-ended to closed-ended questions.

\section{Acknowledgement}

There are many people who are making this humble effort to be a success. Thus, I owe them debts of gratitude. My parents for their financial and moral support. Sincere

\section{Volume 6 Issue 12, December 2017}




\section{International Journal of Science and Research (IJSR) \\ ISSN (Online): 2319-7064 \\ Index Copernicus Value (2016): 79.57 | Impact Factor (2015): 6.391}

acknowledgements go to Mr. David Tarus of AATF for his support in getting primary data to be used in this report and all members of staff in the department of Stats and Actuarial sciences in the school of mathematical sciences particularly the lecturers who taught me. Similarly gratitude goes to all my colleagues in MSc Statistics class of 2014 for their ideas and constructive comments.

\section{References}

[1] CHERN et al: Consumer acceptance and willingness to pay for genetically modified vegetable oil and salmon.

[2] DE groote et al (2002): Maize yield losses from stem borers in Kenya.

[3] DE groote H et al (2004): Debunking the myths of GM crops for Africa: the case of Bt maize in Kenya.

[4] DE groote et al (2003): Assessing the potential impact of Bt maize in Kenya using a GIS based model.

[5] FAO. (2004). FAO (Food and Agriculture organization), 2004. The state of food and agriculture 2003-2004. Agricultural Biotechnology:

[6] Kaneko et al (2003): Consumer Acceptance of Genetically Modified Foods:

[7] LI et al (2003): Consumer attitudes toward genetically modified foods in Beijing, China. AgBioForum, 5(4), 145-152.

[8] Loader, R et al (1998): A view of GMOs from the UK. AgBioForum, 1(1), 31-34

[9] Kimenju et al.Consumer awareness and attitudes toward GM foods in Kenya (2004).

[10] International service for the Acquisition of Agri-biotech Applications (ISAAA) (2011)

\footnotetext{
Appendix

> GLM.2 <- glm (Knowledge_GM Willingness_adopt + Willingness_buy, family=poisson (identity), data=Data)

>summary (GLM.2)

Call:Glm (formula $=$ Knowledge_GM $\sim$ Willingness_adopt

+ Willingness_buy, family $=$ poisson $($ link $=\log )$, data $=$

Data)

Deviance Residuals:

Min 1Q Median 3Q Max

$\begin{array}{lllll}-1.2010 & -0.9016 & 0.3100 & 0.4765 & 0.8401\end{array}$

Coefficients:

Estimate Std. Error t value $\operatorname{Pr}(>|t|)$

(Intercept) $\quad 0.38425 \quad 0.06473 \quad 5.9362 .4 \mathrm{e}-08 * * *$

$\begin{array}{lllll}\text { Willingness_buy } & 0.11361 & 0.08525 & 1.333 & 0.185\end{array}$

Willingness_adopt $0.21375 \quad 0.08495 \quad 2.516 \quad 0.013 *$

Signif.codes: 0 ‘***' 0.001 '**' 0.01 '*' 0.05 ‘' 0.1 ' ' 1

Residual standard error: 0.4882 on 133 degrees of freedom

Multiple R-squared: 0.6459, Adjusted R-squared: 0.5052

F-statistic: 4.592 on 2 and 133 DF, p-value: 0.01179

glm (formula $=$ Knowledge_GM $\sim$ Willingness_buy +

Willingness_adopt, family $=$ poisson $(\operatorname{link}=\log )$ )

Coefficients:

(Intercept) Willingness_buy Willingness_adopt
0.3843
0.1136
0.2137

Number of Fisher Scoring iterations: 5
}

Volume 6 Issue 12, December 2017

www.ijsr.net

Licensed Under Creative Commons Attribution CC BY 